\title{
An Expert-Follower Approach To Enhance Graduate ATtributes In LABORATORY COURSES
}

\author{
Salim Ahmed, Yan Zhang and Darlene Spracklin-Reid \\ Memorial University, St. John's, NL Canada \\ Corresponding Author: sahmed@mun.ca
}

\begin{abstract}
An "expert-follower" approach to conduct laboratory courses is outlined in this article. The main objective of the proposed procedure is to enhance graduate attributes. Two important attributes namely, investigation and team work are focused. In this setting, one team becomes the designated expert team for an experiment. Based on the range of operating conditions of equipment, the expert team will decide different sets of experimental conditions. The expert team will first run the experiment and the follower teams will run in the following weeks, each at a different set of conditions. The follower teams will be briefed by the expert team prior to and during the experiment. The expert team will gather data from the follower teams every week. Each team will be designated expert for one experiment while follower for the others. The expert team will have a large set of data to investigate the characteristics of the corresponding equipment. They will have to analyze data, identify any abnormality and probable causes, and draw conclusions. The success of each team will be mutually dependent and this will be the key for enhancing teamwork skills. This approach will be implemented in a laboratory component of a Term 5 course in the Process Engineering program at Memorial University of Newfoundland. Data on the learning outcomes in a traditional setting are being collected in the current year. The new approach will be implemented during Winter 2016 and data on learning outcomes will be collected to analyze the effectiveness of the approach.
\end{abstract}

Keywords: Engineering, Laboratory, Graduate attributes, Team work, Investigation, Expert-follower.

\section{INTRODUCTION}

Engineering laboratory courses are resource intensive, messy, time consuming and hard to teach [1]. However, enhancement of the graduate attributes through traditionally run laboratory courses is not proportional to the resources utilized. There has been some recent reporting on how to run laboratories for enhancing graduate attributes. An often-prescribed mechanism to improve laboratory outcomes is through effective engagement. Efforts have been made in the past to create a student-centred environment in the laboratory where the students bear the responsibility to decide how to run the experiment [2]. In this approach, students prepare the experimental procedure ensuring that they have a detailed understanding of what they are doing. A model based on Kolb's experiential learning theory was proposed in [3] with a combination of virtual and hands-on laboratories to enhance learning outcomes. A master team approach was proposed in [4] to enhance team work skills in a laboratory course. Renovation aspects of a unit operations laboratory were discussed in [5] with the emphasis to introduce to the students the modern and state of the art of process control. There are other numerous efforts to enhance laboratory teaching using the internet as a tool to run experiments [6], using computer-based simulation along with physical experiments on unit operations [7] and so on. Laboratory experiments are also used to teach complex concepts which are harder to teach from purely theoretical perspectives [8].

Traditionally, laboratory experiments are conducted in a format whereby students are provided with a laboratory procedure to conduct an experiment; they follow the procedure to collect required data, perform analysis of data to obtain prescribed results and write a report. Students find the current format not that much challenging, at least intellectually. Also the low level of complexity may not provide the environment necessary for intense interaction among team members. Albeit the hands-on work provides a feel of the real world and the students can relate the theories learned in the lecture to practical problems. However, much more can be achieved in terms of enhancing graduate attributes by redesigning the procedure; at the same time the laboratory works can be made more interesting as well as challenging for the students.

Although there are a number of alternatives to deductive learning [9], bulk of engineering courses are taught in a deductive manner where principles are taught, 
models are derived, application examples are shown and assessments are carried out to test whether the students are able to solve a similar problem or can explain the principles. On the other hand, the inductive approach starts with an observation followed by its analysis to find the guiding principles [9]. The laboratory courses offer the opportunity to instill inductive learning in the earlier part of a program.

The laboratory component of a course offers the opportunity for context-based learning while the traditional lecture component is mainly devoted to concept-based learning [10]. To benefit from both of the approaches it is important that the laboratory component is designed to be an effective tool for context-based learning and thus indeed becomes complementary to the theoretical component of a course.

The importance of laboratory courses is well recognized and the limitations of traditionally run laboratory experiments are well understood. There is also a surge in redesigning laboratory experiments [3-8]. However, the guiding principles to renovate the experimental laboratories are yet to be established. One approach is to take the enhancement of graduate attributes as the driving force and guiding principle for the purpose of redesign. This paper introduces such an approach, namely the expert-follower approach. The procedure is similar to the master team approach [4] that proposes to develop experimental and team work skills. This article demonstrates that enhancement of a set of graduate attributes can be focused while redesigning a course.

The remainder of the article is organized as follows: Section 2 details the proposed approach; Section 3 discusses the enhancement of the graduate attributes; Section 4 addresses some implementation issues and finally some concluding remarks are made in Section 5.

\section{THE EXPRET-FOLLOWER APPROACH}

In this section, first the general procedure for the proposed approach is discussed followed by details of the procedure in the context of a specific course. A sample laboratory experiment is then detailed to discuss other aspects of the approach.

\subsection{The general procedure}

As the first step, student teams are formed by the instructor and depending on the number of teams, each experiment is assigned one or more designated expert team(s). The other teams will act as followers for that experiment. In the case of more than one expert team for an experiment, follower teams will be grouped and assigned to expert teams. The responsibilities of an expert team are presented in Table 1.
Table 1: List of responsibilities of an expert team.

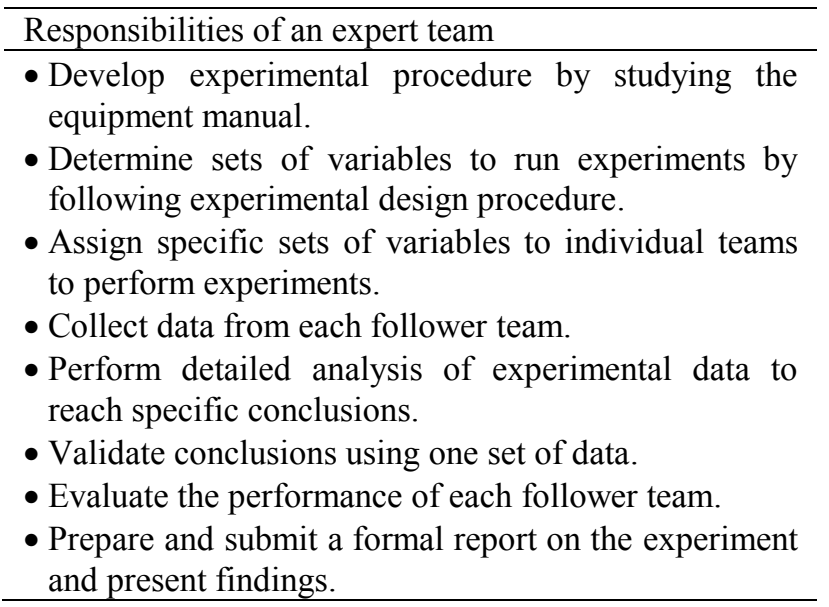

Each team will be a follower for a number of experiments and will have specific responsibilities to meet the objectives of the experiments. Table 2 shows the responsibilities of a follower team.

Table 2: List of responsibilities of a follower team.

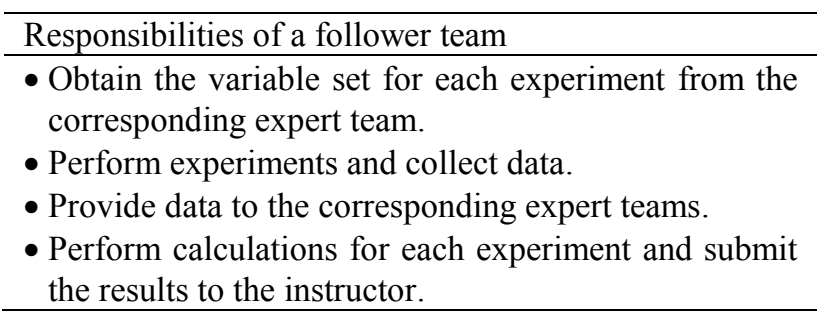

In following the approach, the expert team is expected to demonstrate process leadership whereby one team will influence a set of other teams to achieve a common goal. The expert team assumes an assigned leadership; however, only to establish an interactive relationship with the followers. Although the expert team will have influence on the follower teams, the power base is only on expertise that the expert team learns in the process of designing the experiment. The expert team will evaluate the quality of work of the follower teams and submit their evaluation to the instructor; thus they will assume a bit of reward power as well.

\subsection{Course specific implementation}

The proposed approach will be implemented in a course on unit operations offered to Term 5 students in the Process Engineering program at Memorial University, St. John's. The first implementation will be during Winter 2016. Ten teams will be formed and five experiments will be conducted by each group. Two teams will be the expert 
teams for each experiment. Four teams will follow each expert group.

Having 10 groups, each experiment can be conducted at 10 unique combinations of operating conditions. The two expert teams designated for each experiment will work together to identify and finalize the operating conditions that they would like to run the experiments. Students' prior knowledge of experiment design methodology will be used to determine the operating conditions. During the first week, the concepts of experiment design will be taught as part of the laboratory.

Following is the list of experimental set-ups students will use to conduct experiments:

1. Shell and tube heat exchanger

2. Plate and frame filter press

3. Ball mill

4. Mixing apparatus

5. Fluidized bed

Each experiment can be run at different operating conditions and modes. As an example, the heat exchanger set-up is discussed in detail in the following section.

\subsection{A sample laboratory experiment}

The shell and tube heat exchanger is a table-top experimental set-up. The objective of the experimental study is to investigate the effect of operating parameters on the heat transfer efficiency and heat transfer coefficient. The set-up has the options to run in both cocurrent and counter-current mode. Cold water is heated in the exchanger using hot water. The flow rates of both hot and cold water can be changed. The temperature of hot water can also be changed. Thus there are four operating variables available for manipulation; namely, mode, cold water flow rate, hot water flow rate and hot water temperature. The mode being binary and the other variables being continuous, it is possible to run the experiment at many different operating conditions. However, during a three-hour laboratory session it is not possible to conduct the experiment at more than four different operating conditions as it requires approximately half an hour for the temperatures to reach steady state after a change is made. With 10 groups running the experiments at 10 different sets of conditions, a large set of data can be collected to meet the objective of the study. This will also allow the expert teams to perform in-depth analysis to reach substantial conclusions. Students will also be able to validate their conclusions using one set of data for cross-validation.

\subsection{Team formation}

In the proposed procedure, teams will be formed by the instructor. Performance of the students in their previous terms will be used to form teams having members with different levels of academic performance. This will allow for maintaining heterogeneity within a team while no team will have undue disadvantage with only having low performing members.

\subsection{Assessment of team work}

From an assessment perspective, evaluation of team work requires that the individual members develop an ability to work in a team. This can be measured in terms of performance, behavior and attitude. We plan to assess individual performance using evidence of contribution. Each team member will require outlining their individual contribution in a one page document submitted separately to the instructor. Behavior will be assessed by independent observations by the instructors and the teaching assistants during the laboratory sessions and during meetings with the teams. Attitude will be assessed by peer assessment using a questionnaire [14]; a sample questionnaire is presented in Table A.2. Peer assessment is established as a valid assessment procedure. It also help to develop team work skills; learning how to provide feedback on peers' performance, give and accept criticism, justify one's position are all forms of social and assertion skills [15]. Each member will be required to perform self and peer review by mentioning on a 5 tier scale whether they agree or disagree with each statement in a list. The three measures of individual assessment will be used to assign individual grade for a fraction of total marks on the formal report. Part of the final presentation will also be graded individually. Thus team performance as well as individual performance will be assessed.

\subsection{Grading scheme}

In the proposed approach, more emphasis is on one experiment for a particular group. It is expected that the designated expert team for an experiment will have an indepth understanding and mastery of the corresponding subject matter while having a basic understanding of the operating principles of the other experiments for which they play the follower role. Logically, for a team, the experiment for which the team plays the expert role will have more weightage in marking. To accommodate peer review, each team will evaluate the performance of the follower teams by answering to a set of questions. The evaluation will be an indirect indicator of the performance of the teams.

To highlight the importance of safety and to make students aware of the consequences of violations of safety, a small percentage of marks will be allocated to laboratory safety performance. Any team with a major safety violation will be penalized the entire marks on safety 
performance. Any minor violation will result in partial penalty. A list of safe operating guidelines will be provided to the students during introduction to make them aware of the safety issues.

\section{THE GRADUATE ATTRIBUTES}

Socio-economic and cultural changes are imposing challenging requirements on teaching and learning. To cope with the changing requirements, quality control measures are being put in place to maintain the quality of graduates. The Canadian Engineering Accreditation Board (CEAB) prescribes a list of hard as well as soft skills which a graduate should acquire through a program. Laboratory courses can be designed to enhance most of the graduate attributes prescribed by the CEAB. Although the proposed approach has a set of outcomes, two important attributes, namely, investigation and team work have been the foci in the development of the approach.

\subsection{Team work}

Effective teaching requires organizing learning opportunities in social contexts by enabling students to learn together. Having students to teach students can create the appropriate social context and create a sense of learning community. The role of the teachers then becomes to help students in developing their work ethics and individual behavior and attitude in the context of a team environment.

Leadership, in a social context can be an innate characteristic (trait leadership). However, in the context of a program outcome, leadership refers to process leadership which is a set of properties that can be learned. $\mathrm{CEAB}$ prescribes individual and team work as a required graduate attribute that encompasses both the ability to work in a team environment as well as to lead a team.

The proposed setting allows for a two-tier team environment. Within a team, individuals are the building blocks while each team forms the building blocks and makes the entire class work as a team. Within a team the members can assess and analyze the problem from different viewpoints, do their individual research on the topic, share opinion and knowledge while value others opinion and finally can reach to a decision/conclusion; these are the aspects of mutual accountability and complementary skills. The interaction among teams will foster the aspects of interdependence. The performance of the expert team will depend on the performance of the follower teams. At the same time, as all teams will be expert for one experiment, they will be totally aware of mutual dependence among teams. It is worthwhile to mention that the objective is to develop the individual skills of the team members; the performance of a team as a whole is just one indirect indicator of individual performance.

Most importantly, one needs to ensure that the team works do not turn into mere group works where individuals can work independently without developing a synergy [11]. The interdependent nature resulting from the proposed approach will ensure synergic effort to reach a common goal. The broad scope of work will ensure that the individual members share information and insight to meet the objective of the work.

\subsection{Investigation}

Investigation requires a higher level of understanding beyond mere factual knowledge. Students should be able not only to interpret data, they should be able to generalize results to construct knowledge, predict outcome scenarios, categorize equipment in terms of their use, identify operational imitations of equipment, propose modification of the equipment for the purpose of redesign and justify any suggested modification.

Investigation as an attribute refers to an ability to conduct investigations of complex problems by methods which include appropriate experiments, analysis and interpretation of data and synthesis of information in order to reach substantiated conclusions. However, in many cases the laboratory activities are limited to analysis and to some extent interpretation of data. Students have little or no say on the design of experiments and data from a single experiment may not be enough to generalize results. In the proposed approach through design of experiments students will be able to define their own experiments and will have access to a large set of data to draw substantiated conclusions.

\subsection{Other graduate attributes}

Project management is one of the skills that graduates need to develop. From a management perspective, time is a critical component and time management skills can be better developed by undertaking long term project. The proposed approach will require the entire team to perform time bounded milestone activities spread over the entire term and thus will help to develop project management skills which can be further sharpen during their final term when they do the capstone design project.

Communication skills are becoming more and more important in the current engineering contexts where product and process development need to consider global economic, social and environmental as well as manpower aspects. The proposed approach will require not only communication among team members but also an effective communication among teams in a mutually interdependent environment. This will facilitate to 
develop interpersonal skills. To develop writing and verbal communication skills, students will have to submit a detail formal report and present the findings of their work to the entire class and to the instructional team.

\section{IMPLEMENTATION ISSUES}

There are several implementation issues that need attention and perhaps re-evaluation.

\subsection{Instructor selected team}

When students self-select their teams, often teams become more homogeneous and this is not beneficial for team work. Sometimes, better performing students group together and make their work less challenging. This may make intense interactions among the members to become less frequent. Also, students may form teams with classmates they consider friends; this may make the practice of individual accountability to be less prevailing. Research findings indicate that teams formed by the instructor perform, on an average, better than students' self-selected teams [12].

However, there are challenges when the instructor selects the teams. The duration for the team work will be for the entire term. If a team is found to be highly dysfunctional, there will be no escape. During the midterm evaluation, each team will discuss their challenges and the instructor will meet each team to identify any dysfunctional situation. In the extreme case, low level reshuffling of the teams may be allowed.

\subsection{Assessment of team work}

CEAB defines the individual and team work attribute as an ability to work effectively as a member and a leader in a team, preferably in a multi-disciplinary setting. There has been lot of discussions on whether the soft skills can be taught and assessed [13]. It should be clear on the part of the assessor that the assessment is not on whether the team performed as expected. On the contrary, the objective is to assess whether the individual members performed in a team. How well a team functions as a whole is not a clear indicator that all of the members performed as required.

The effectiveness of a member in a team can be assessed in terms of performance, behavior and attitude [11]. Performance refers to whether a member completed his task properly, introduced new idea, and gathered new information and did research. Behavior refers to whether the member did his/her job in a timely manner and expressed himself/herself clearly and openly. Attitude refers to whether the member listened to and valued other members' opinions, helped others and solicited help from others, and distinguished between important and trivial. Individuals within a team can be assessed by independent observations by the instructor and teaching assistants, using evidence of contribution by monitoring team activities and by peer review.

A critical aspect of assessment is that one needs to assess whether an individual developed the corresponding skills by undertaking an activity. If the team work skills are listed outcomes of a course, one needs to ensure that the performance, behavior and attitude of the individual members of the team are enhanced by undertaking the course activities.

\subsection{Work-load and marking scheme}

It is important to balance the workload of the students according to the weight of the assessment item in the overall marking scheme of the course. The laboratory component of the course is worth $30 \%$ of the total marks. To balance workload student will have to submit a formal report for the experiment for which they play the expert role. For other experiment they need to submit the results and discussion on results. Safety plays an important role in the day-to-day activities of a professional engineer. A small fraction of mark is assigned to assess safety performance.

\section{CONCLUDING REMARKS}

For an engineering program, laboratory is an integral and important component. From a resource utilization perspective, laboratory courses are costly. However, if an experiment is not well designed, students may not find it thought provoking and challenging. Also, poorly designed laboratories may not meet the outcome requirements. In this article we propose an approach as an effort to renovate the operation of a laboratory course. It does not require any additional resources; however, students need to play a more active, engaged and responsible role. The objective is to enhance certain attributes of the graduates in a team environment. Students will play the role of an expert for an experiment while they will follow others for other experiments. Thus, an expert-follower approach is formulated. The proposed procedure is expected to enhance the teamwork and investigation skills as well as a number of other attributes. The proposed method is yet to be implemented. However, we believe that we need to stir discussions on all possible levels to identify the shortcomings of the approach. It is only through discussion and collaboration that we can experience the much-required changes in teaching and learning, and help our students in gaining the attributes that they require. 


\section{References}

[1] Phillip C. Wankat and Frank S. Oreovicz, Teaching Engineering, McGraw-Hill, Inc., 1993.

[2] Salim Ahmed, Syed Imtiaz, Lesley James, and Darlene Spracklin-Reid, "Designing laboratory procedures to enhance graduate attributes", CEEA 2013, June 2013, Montreal, QC, Canada.

[3] Mahmoud Abdulwahed, and Zoltan Nagy, "Applying Kolb's experiential learning cycle for laboratory courses" $J$. Engr. Education, July 2009, 283-294.

[4] Clemence Fauteux-Lefebvre, Denis Gravelle and Nicolas Abatzoglou, "In-depth learning and development of experimental and team work skills in laboratory courses," CEEA 2013, June, 2013, Montreal, QC, Canada.

[5] Graeme Norval, Paul Szabo, Glenn Wilson, and Paul Jowlabar, "A new approach to the unit operations laboratory at the University of Toronto". CEEA 2011., St. John's, NL.

[6] Victor Skormin and Vladimir Nikulin, "Engineering Laboratory Accessible via the Internet", Proc. 2001 ASEE Conf., Albuquerque, New Mexico, June 2001.

[7] Theodore Wiesner and William Lan, "Comparison of student learning in physical and simulated unit operations expts" J. Engr. Ed., 93(3), 195-204, 2004.

[8] Karl Johansson, Alexander Horch, Olle Wijk, and Anders Hansson, "Teaching multivariate control using the quadruple-tank process," Proc. $38^{\text {th }}$ Conf. on Decision and Control, Phoenix, AZ, USA, December 1999.

[9] Michael J. Prince and Richard M. Felder, "Inductive teaching and learning methods: Definitions, comparisons, and research bases," J. Engng Ed., 95(2), 123-138, 2006.

[10] Zhao Y. Dong, "Improving learning in undergraduate control engineering courses using context-based learning models," Int. J. Engng Ed., 21(6), 1076-1082, 2005.

[11] Karl Perusich, Beverly Davis, Gil Laware and Kevin Taylor, "Assessing teamwork for accreditation: Understanding what needs to be known and its integration into engineering and technology curricula," $37^{\text {th }}$ ASEE/IEEE Frontiers in Ed. Conf., Oct 10-13, Milwaukee, WI 2007.

[12] Richard M. Felder, Donald R. Woods, James E. Stice, Armando Rugarcia, "The future of engineering education ii. Teaching methods that work", Chem. Engr. Ed, 34(1), 2639 (2000).

[13] Larry J. Shuman, Mary Besterfield-Sacre, Jack McGourty, "The ABET professional skills - Can they be taught? Can they be assessed?" J. Engr. Education, Jan 2005, 41-55.

[14] Robert W. Lingard, "Teaching and assessing teamwork skills in engineering and computer science", Journal of Systemics, Cybernetics and Informatics, 18(1), 34-37.

[15] Keith Topping, "Peer assessment between students in colleges and universities," Review of Ed. Res., 68(3), 249$276,1998$.

\section{APPENDIX A: SCHEDULE AND QUESTIONNAIRE}

\section{A.1 Schedule}

Table A.1: Schedule of term-wide activities.

\begin{tabular}{|l|l|}
\hline Week & Activities \\
\hline 1 & $\begin{array}{l}\text { Instructor } \\
\text { - forms teams and announces } \\
\text { - presents the laboratory procedure and outlines } \\
\text { the responsibilities of expert teams and } \\
\text { follower teams. } \\
\text { - distributes laboratory manuals and outlines } \\
\text { assessment criteria. } \\
\text { - allocates follower teams in the case of more } \\
\text { than one expert team for an experiment. }\end{array}$ \\
\hline 2 & $\begin{array}{l}\text { - Expert teams prepare laboratory procedure } \\
\text { and determine the set of operating conditions }\end{array}$ \\
\hline 3 & - Expert teams perform laboratory experiments \\
\hline $4-11$ & $\begin{array}{l}\text { - Follower teams perform experiments } \\
\text { - Follower teams share data with expert teams } \\
\text { and submit calculations and results } \\
\text { - Expert teams continue working on data } \\
\text { analysis and report }\end{array}$ \\
\hline 7 & $\begin{array}{l}\text { - Mid-term presentation by all teams } \\
\text { - Mid-term evaluation of team performance. }\end{array}$ \\
\hline 12 & $\begin{array}{l}\text { - Expert teams submit final report and present } \\
\text { their findings. }\end{array}$ \\
\hline
\end{tabular}

\section{A.2 Sample questionnaire}

Table A.2: Peer review questionnaire to evaluate attitude.

\begin{tabular}{|c|c|c|c|c|c|}
\hline $\begin{array}{l}\text { Indicate to what extent you } \\
\text { agree with the following } \\
\text { statement about } \\
\text { Team member: First Last }\end{array}$ & 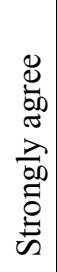 & $\begin{array}{l}\stackrel{0}{D} \\
\stackrel{0}{00} \\
\gtrless\end{array}$ & $\begin{array}{l}\bar{\pi} \\
\stackrel{\Xi}{0} \\
\bar{z}\end{array}$ & 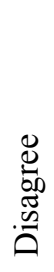 & 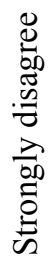 \\
\hline $\begin{array}{l}\text { 1. Shared knowledge and } \\
\text { opinion. }\end{array}$ & & & & & \\
\hline $\begin{array}{l}\text { 2. Valued others' opinion and } \\
\text { accept suggestions. }\end{array}$ & & & & & \\
\hline 3. Helped other team members & & & & & \\
\hline 4. Sought help from others & & & & & \\
\hline 5. Showed respect to others & & & & & \\
\hline $\begin{array}{l}\text { 6. Distinguished between the } \\
\text { important and the trivial. }\end{array}$ & & & & & \\
\hline
\end{tabular}

